\title{
Autism Spectrum Disorder with the Perspective of Etio- Pathogenesis; Enviremantal, Genetic, and Epigenetic Factors
}

\section{Etiyo-Patogenez Perspektifi ile Otizm Spektrum Bozukluğu; Çevresel, Genetik ve Epigenetik Faktörler}

\author{
Recep Kesli', @Mine Dosay Akbulut ${ }^{2}$ \\ 'Selçuk University, School of Medicine, Department of Medical Microbiology, Konya, Turkey \\ ${ }^{2}$ Afyon Kocatepe University, Faculty of Veterinary Medicine, Department of Medical Biology and Genetics, Afyonkarahisar, Turkey
}

\section{Dear Editor,}

Autism Spectrum Disorder (ASD) is a neurodevelopmental disorder that is charecterized with deficits in social skills (communication and interaction), language skills and presence of steriotypical repetetive behaviours, and interests or activities that can persist throughout life. ${ }^{[1]}$ ASD prevalance was recently reported with an increase at 1 in 59 children by Center for Disease Control and Prevention (CDC) USA. ${ }^{[2]}$

Although definite etiology of the ASD is still unclear; different evidences were determined from many conclusions of the studies suggesting and supporting etiologic and causative associaton of three factors (enviremental, genetic and epigenetic factors) with ASD. Each factor has two or three sided interaction with each other. Intestinal microbiota homeostasis is one of the most important element of environmental factors. ${ }^{[3,4]}$

Human gut microbiota consisting of more than three thousand of different bacterial species belonging to six different phyla and ten fold higher than cell numbers of human body. Human gut microbiota has bidirectional commnuciation (cross-talk) with the human brain called as microbiota gut brain axis (MGBA) via determined four different pathways; 1 . Metabolic pathway 2. Neural (neuronal) pathway 3. Neuro-endocrin pathway 4. Immunologic pathway. ${ }^{[4]}$ Perinatal maternal microbiota composition changes (density and diversity) resulting with maternal dysbiosis altering expression of the genes related with autism etiology (CC2D1A, SHANK1-3, CASPR2, CNTNAP2, BRSK2) and also epigenetic mechanisms. Maternal dysbiosis also results in regression of fetal neuerodevelopment and maturation of neuronal and brain cell of the fetus at intrauterin period. Maternal dysbiosis at perinatal period may also triggers maternal immun activation that may also have a negative affect on fetal neural development. Neuronal connectivity and signal transmisison impaired as a result of the explained neuroimmuno pathologies triggered with perinatal maternal dysbiosis. Accession of toxic and harmful molecules to brain is blocked by two major barriers: Bowel Brain Barrier (BBB) and Blood Brain Barrier (BBB) ${ }^{[5]}$ Integrity of the two barriers are maintained by functions of tight junction proteins. Barrier functions are obtained and protected by eubiosis of intestinal microbiota. Dysbiosis leads to impairment of barrier functions and results in increased intestinal permability. Short chain fatty acids (propionate, acetate, butyrate) are components of the cellular membrane of especially two anaerobic species (Bacteroides spp., and Clostridium spp.) and they can also be derived from fermentation of complex carbohydtrate molecules such as inulin in the intestine. Propionic acid (PPA) is a potent activator of pro enflammatory cytokines (IL1 $\beta$, TNFa, IL6) synthesis, and can reach to the brain and initiates neuroenflammation. Overgrowth of Bacterodies 
and Clostiridum strains in the intestinal microbiota results in excessive production of PPA and initiates the neuroimmunopathologic changes that is one of the known mechanisms of autistic brain. ${ }^{[4,5]}$

Etio-pathogenesis of the neuro-immunopathologic changes in the autistic fetal brain can be explained with perinatal maternal dysbiosis, which causes alterations in maternal and fetal gen expressions, epigenetic mechanisms, maturation of neuronal cells and fetal neurodevelopment, concluding with abnormal neural signal transmisison, and maternal immune activation.

\section{ETHICAL DECLARATIONS}

Referee Evaluation Process: Externally peer-reviewed.

Conflict of Interest Statement: The authors have no conflicts of interest to declare.

Financial Disclosure: The authors declared that this study has received no financial support.

Author Contributions: All of the authors declare that they have all participated in the design, execution, and analysis of the paper, and that they have approved the final version.

\section{References}

1. American Psychiatric Association. Diagnostic and statistical manuel of mental disorders. 5th ed. Arlington, VA: American Psychiatric Association; 2013.

2. Baio J, Wiggins L, Christensen DL et al. Prevalence of Autism Spectrum Disorder Among Children Aged 8 Years - Autism and Developmental Disabilities Monitoring Network, 11 Sites, United States, 2014. MMWR Surveill Summ 2018;67(6):1-23.

3. Sharon G, Cruz NJ, Kang DW, et al. Human gut microbiota from Autism Spectrum Disorder promote behavioral symptoms in mice. Cell 2019;177(6):1600-1618.e17.

4. Lasheras I, Seral P, Latorre E, Barroso E, Gracia-García P, Santabárbara J. Microbiota and gut-brain axis dysfunction in autism spectrum disorder: Evidence for functional gastrointestinal disorders. Asian J Psychiatr 2020;47:101874.

5. Roman P, Rueda-Ruzafa L, Cardona D, Cortes-Rodríguez A. Gut-brain axis in the executive function of austism spectrum disorder. Behav Pharmacol. 2018; 29(7):654-63. 